\title{
Effective FEA design of hard face composite structures to stop armor piercing projectiles
}

\author{
G. A. Forental \& S. B. Sapozhnikov \\ Physics Department, South Ural State University, Russia
}

\begin{abstract}
Traditional ceramic/composite personal protective structures now are monolithic. In this case, the ceramic part is designed to shatter the high hardness core of the projectile into fragments and the role of the composite part is full dissipation of the residual energy of these fragments. In order to stop a 7.62 calibre armor piercing projectile (B-32), the current design of an alumina/aramid fibre reinforced plastic structure consists of $10 \mathrm{~mm}$ of alumina and $10 \mathrm{~mm}$ of composite backing, so the areal density is about $50 \mathrm{~kg} / \mathrm{m}^{2}$. In this work, we designed ceramics/sandwich composite protective structures, which have less weight and cost than traditional ones. To make the FEA optimization procedure of the new structure faster we developed novel low-parametric failure models of ceramics and FRPs. For alumina ceramic we proposed pseudo-brittle (with plasticity only at compression, strain rate insensitive tension strength) failure model. The failure model of a layered composite has two mechanisms: brittle fibre's breakage and delamination (breakable layer's contacts). We used ANSYS/AUTODYN-3D explicit code with a 'death of elements' approach and the remaining eroded element's inertia.

Keywords: ceramics, composite backing, FEA, AP bullet, sandwich structure.
\end{abstract}

\section{Introduction}

Modern ceramics/FRP protective structures are widely used to defeat armor piercing (AP) bullets due to low areal density, high face hardness and the ability to dissipate the bullet and ceramic fragments energy by the fibre's fracture and delamination (Hazell [1]). The best compositions nowadays consist of boron or silicon carbide face layer and UHMWPE backing plate, (Ong et al. [2] and Bürger et al. [3]). Areal density is about $30-35 \mathrm{~kg} / \mathrm{m}^{2}$ (Level III, STANAG 4549, 7.62 AP 
B-32 bullet, $840 \mathrm{~m} / \mathrm{s}$ ). These projects are used for personal protection (Bürger et al. [3] and Holmquist and Johnson [4]), where the minimum weight is mostly demanded. But for the ground vehicle armor there are frequently used combinations of alumina/aramid fibre reinforced plastic (AFRP) backing plate (Danzer [5]). At the same loading conditions (Level III, STANAG), areal density of this combination is about $50-52 \mathrm{~kg} / \mathrm{m}^{2}$. Monolithic alumina plate is nice to stop for only one shot, because multiple radial cracks after first impact decrease the reliability of that protective structure for next impacts (Levy and Molinari [6] and Lee et al. [7]). Pelletizing of alumina block is the modern way to construct multihit protection (Clayton [8]), but weight goes up 10-15\% because of weak zones near the borders of ceramic tiles/pellets. In this case, we need to save weight from the composite backing part by using, for example, a sandwich structure instead of a monolithic one. A very close analogy could be taken from space hypervelocity impact protection (Whipple shields with aluminium and Nextel-Kevlar bumper layers [9]). An external, thin bumper shield that is exposed to the debris flux and causes the impactors to completely disintegrate during impact (full analogy with ceramic facing layer). The resulting cloud of projectile debris and bumper material that forms behind the bumper leads to a much wider spatial distribution of momentum, allowing the back face of the shield to withstand the impact pressure.

The current study investigates and demonstrates the relationships between residual velocity of AP projectile after penetration of ceramics/composite target and dimensional parameters of this target. Experimental data to validate numerical models of ceramics and FRPs are described. The effect of sandwich skin thickness ratio on the overall armor ballistic performance will be presented, following the numerical model and simulation results.

\section{Experimental}

\subsection{Modelling materials}

To understand the basics of alumina/AFRP target penetration by high hardness AP projectile we have chosen firstly the commercially available modelling materials: $4.84 \mathrm{~mm}$ of thickness soda-lime glass (as 'ceramic layer'), $2 \mathrm{~mm}$ of thickness GFRP 'STEF' (as 'AFRP laminate' with close mechanical behaviours) and 6.35 $\mathrm{mm}$ of diameter tempered steel ball (as 'AP projectile' with close to high hardness core mechanical behaviours).

These modelling materials were tested under static and different dynamic conditions:

1. Weighing to get density;

2. Tension of GFRP coupons in warp, weft and diagonal directions to estimate elastic modules and strength using quasi-static testing machine INSTRON 5882;

3. Ring-on-ring bending test to determine the tensile strength of glass;

4. High velocity impact tests of materials by use of steel ball to get ballistic curves.

All data of 1-3 items are collected in Table 1. In brackets, there are fitted dynamic strength data for glass and GFRP after ballistic penetration and numerical calculations. 
Table 1: Mechanical behaviours of materials.

\begin{tabular}{|l|c|c|c|c|}
\hline Material & $\begin{array}{c}\text { Density, } \\
\mathrm{g} / \mathrm{cm}^{3}\end{array}$ & $\begin{array}{c}\text { Modules of } \\
\text { elasticity, GPa }\end{array}$ & $\begin{array}{c}\text { Poisson's } \\
\text { ratios }\end{array}$ & $\begin{array}{c}\text { Strength, } \\
\mathrm{MPa}\end{array}$ \\
\hline $\begin{array}{l}\text { Soda-lime } \\
\text { glass }\end{array}$ & 2.50 & 73 & 0.20 & $\sigma_{\mathrm{u}}=95(200)$ \\
\hline $\begin{array}{l}\text { Tempered } \\
\text { high carbon } \\
\text { steel [10] }\end{array}$ & 7.85 & 210 & 0.30 & $\begin{array}{c}\sigma_{\mathrm{yield}}=1300 \\
\sigma_{\mathrm{u}}=1800 \\
\mathrm{E}^{\text {tangent }}=13000\end{array}$ \\
\hline $\begin{array}{l}\text { GFRP } \\
\text { 'STEF', } \\
\text { x-warp, } \\
y \text {-weft }\end{array}$ & 2.00 & $\begin{array}{c}\mathrm{E}_{\mathrm{x}}=\mathrm{E}_{\mathrm{y}}=27.0, \\
\mathrm{E}_{\mathrm{z}}=8.0, \\
\mathrm{G}_{\mathrm{xy}}=4.0, \\
\mathrm{G}_{\mathrm{xz}}=\mathrm{G}_{\mathrm{yz}}=3.5\end{array}$ & $\begin{array}{c}v_{\mathrm{xy}}=0.15, \\
v_{\mathrm{xz}}= \\
0.40, v_{\mathrm{yz}}= \\
0.40\end{array}$ & $\begin{array}{c}\sigma_{\mathrm{ux}}=\sigma_{\mathrm{uy}}=410 \\
(900)\end{array}$ \\
\hline
\end{tabular}

The ballistic tests were performed using the $6.35 \mathrm{~mm}$ of diameter tempered steel ball accelerated (with LDPE small sabot) up to $900 \mathrm{~m} / \mathrm{s}$ by the energy of standard civil dowel cartridge on special lab-scale stand (Sapozhnikov et al. [11], Figure 1).

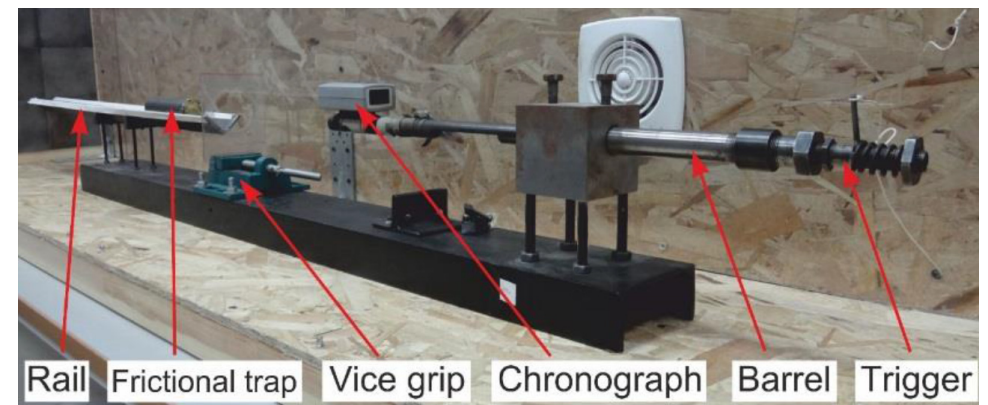

Figure 1: Lab-scale gunpowder stand.

Initial bullet velocity $V_{i}$ was measured by the optical chronograph and residual velocity $V_{r}$ (after penetration of target) was measured by special frictional trap. Sliding distance $S$ of the trap along rail at dry friction conditions vs $V_{r}$ was calibrated by ball shots without target. All ballistic experiments' data were collected as $V_{r}$ vs $V_{i}$ graphs (ballistic curves) and then least-squares fitted by use of classical Lambert-Jonas formula:

$$
V_{r}=\left\{\begin{array}{c}
0, \quad \text { if } V_{i}<V_{L} \\
A \cdot\left(V_{i}^{k}-V_{L}^{k}\right)^{\frac{1}{k}}, \quad \text { if } V_{i} \geq V_{L}
\end{array},\right.
$$

where $V_{L}$ is ballistic limit, $A$ and $k$-regression parameters.

\subsection{Numerical modelling}

In this part, we will discuss the methodological problems to work with brittle materials like glass or ceramics and composites. In literature, we can find out 
different failure models, but most popular ones are Johnson-Cook (JC) and Johnson-Holmquist $(\mathrm{JH})$ failure models of ductile or brittle materials (Johnson and Holmquist [12] and Johnson [13]), which have up to 20 parameters to determine before calculations. It needs to be said that these models were developed for a wide range of loading conditions: from low up to ultra-high speed impacts. There are a few materials with known all data for JC or JH models embedded into software like AUTODYN.

If we are going to use narrower loading conditions, it's better to take simpler models with lesser parameters to predict ballistic performance because of significant cost of experimental works to define all JC or JH models' parameters.

In this work, impact velocities are in the range of $100-900 \mathrm{~m} / \mathrm{s}$, when the compressibility of dense solids (glass, GFRP, ceramics) is not so high, strain rates are about one order and all mechanical behaviors can be insensitive of strain rate. Quasi-static values of strength characteristics should be increased (typically in 22.5 times) to fit the experimental data of ballistic impact. Therefore, for ceramics in described conditions we can construct stress-strain law as the law of isotropic incompressible elastic-plastic media that will fail when the first principal stress achieving corresponding tensile strength (Figure 2(a)).

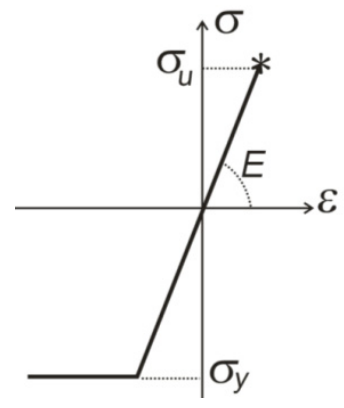

(a)

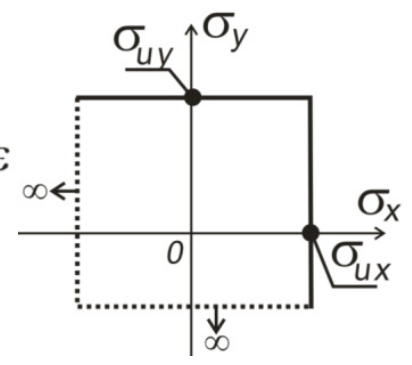

(b)

Figure 2: $\quad$ Failure models of ceramics (a) and GFRP (b).

This simple model reflects the most valuable feature of ceramics: brittleness at the tension and pseudo ductility at compression. We can say that ductility of ceramics now is very popular item especially at indentation (compression) [1416]. But in our model there are no any cracks or micro damages and only 'death of finite elements' (with remaining of inertia) is in the FE calculations. So we substituted compressive plasticity and cracks' mechanisms by only plasticity (with lesser yield stress in comparison with apparent compressive yield stress at the micro indentation tests) to indirectly get the same dissipation energy.

For GFRP the model of material is orthotropic elastic. Failure is stress driven along warp and weft directions achieving corresponding tensile strength. This is assumed because fibers in FRP are the strongest and most energy consuming parts. Matrix stiffness is low and energy of fracture is low too. So, we consider that all shear and transversal compressive strength can be taken as infinite (1e20 Pa during calculations) (Figure 2(b)). 
Layered GFRP can also be damaged during transversal tension leading to delamination. In our protective structures all bonded contacts were modeled as breakable (tensile and shear strength are $50 \mathrm{MPa}$ ) to get realistic value of delamination area. Material of tempered steel ball was assumed to be elasticplastic.

ANSYS/AUTODYN explicit software offers to erode FE from the mesh if its distortion became great (Geometric Strain Limit $>1$ ). This approach helps to prevent of drastically reducing of time step and to limit the dissipation energy of distorted FE.

The next factor is the size of the FE mesh at the modelling. To predict FE failure, explicit software like ANSYS/AUTODYN or LS-DYNA uses FE with one integration point. Therefore, the gradient of stress or strain at failure of FE is not considered [17]. This is obviously the indirect mechanism to include the toughness of material in numerical modelling (toughness is the instrument to measure of material sensitivity to stress/strain gradient). Smaller size of FE - lesser toughness of the material. Preliminary impact calculations in the range closed to ballistic limit showed that the rational size of FE mesh of glass, alumina and FRP must be $1 \ldots .2 \mathrm{~mm}$.

Experimental and numerical results of penetration of glass plate, GFRP and combination of glass/GFRP depicted in Figure 3. Tested plates were vice-gripped by one side. Pictures of penetrated plates are shown in Figure 4.

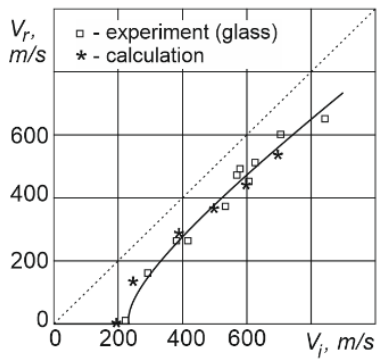

(a)

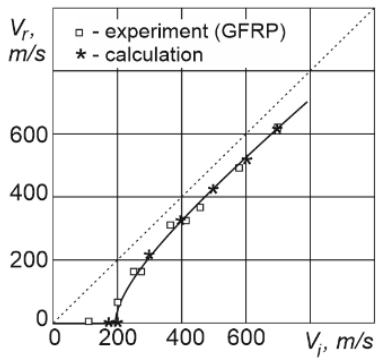

(b)

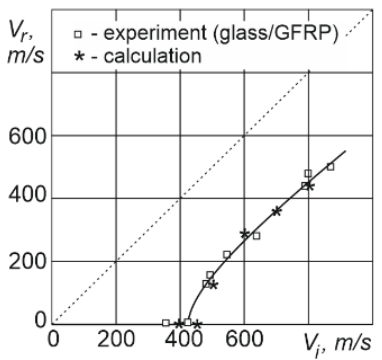

(c)

Figure 3: Ballistic curves for glass (a), GFRP (b) and glass/GFRP (c). Lines approximations of experimental data by Lambert-Jonas (eqn (1)).

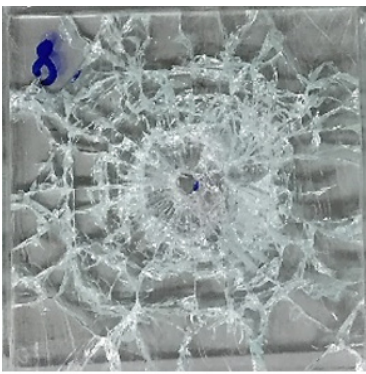

(a)

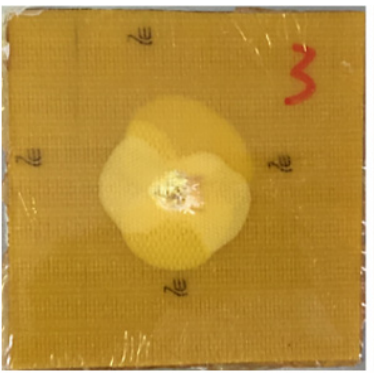

(b)

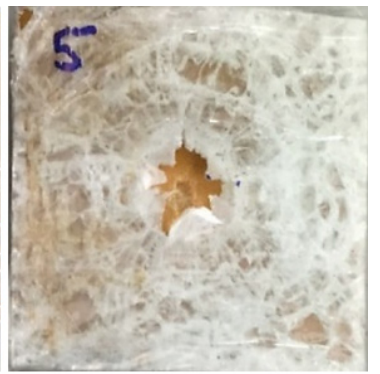

(c)

Figure 4: Samples $(100 \times 100 \mathrm{~mm})$ of glass (a), GFRP (b) and glass/GFRP (c). 
A very good comparison of ballistic tests and numerical results for penetration of glass, GFRP and layered glass/GFRP structure gave us the possibility to estimate ballistic performance of alumina/AFRP composite with use the same simple 'pseudo-brittle' low-parametric approach.

\section{Ballistic performance of alumina/AFRP composite}

\subsection{Monolithic protective structures}

Taking threat level III of STANAG 4849 with $7.62 \times 54$ AP B-32 $(840 \mathrm{~m} / \mathrm{s})$ projectile this is known that combination of $10 \mathrm{~mm}$ of alumina thickness and $10 \mathrm{~mm}$ of thickness AFRP block can defeat this threat (Ogorkiewicz [18]). AP B32 projectile consists of high hardness steel core ( $\sim 68 \mathrm{HRC})$, and low-carbon steel jacket (Figure 5). The jacket was modelled by elastic-plastic steel with yield stress $\sigma_{\mathrm{y}}=150 \mathrm{MPa}$, the core was pseudo-brittle steel with $\sigma_{\mathrm{y}}=1300 \mathrm{MPa}, \sigma_{\mathrm{u}}=1800 \mathrm{MPa}$. $60 \%$ of the bullet core length was designed to be eroded and back $40 \%$ was elasticplastic and non-fractured. This reflects the experimental observations with tempered steel cores after penetration of ceramics/composite tiles. Alumina was pseudo-brittle (elastic-plastic) isotropic media with $\sigma_{\mathrm{y}}=\sigma_{\mathrm{u}}=1350 \mathrm{MPa}$, $\mathrm{E}=390 \mathrm{GPa}, v=0.22$. AFRP was modelled by orthotropic media with $\mathrm{E}_{\mathrm{x}}=\mathrm{E}_{\mathrm{y}}=$ $40 \mathrm{GPa}, \mathrm{E}_{\mathrm{z}}=8 \mathrm{GPa}, \mathrm{G}_{\mathrm{xy}}=3 \mathrm{GPa}, \mathrm{G}_{\mathrm{xz}}=\mathrm{G}_{\mathrm{yz}}=2 \mathrm{GPa}, v_{\mathrm{xy}}=0.14, v_{\mathrm{xz}}=0.3, v_{\mathrm{yz}}=0.3$, $\sigma_{\mathrm{ux}}=\sigma_{\mathrm{uy}}=1000 \mathrm{MPa}, \sigma_{\mathrm{uz}}=50 \mathrm{MPa}$. Size of FE mesh for ceramics, AFRP and bullet was in a range of $1 . .2 \mathrm{~mm}$ to get realistic fragmentation and picture of penetration.
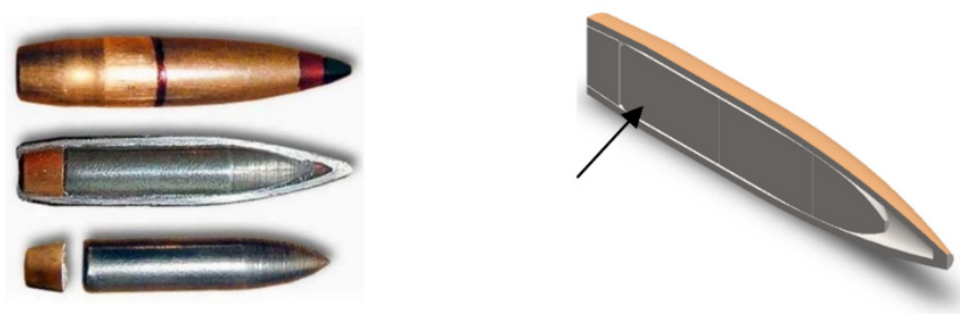

Figure 5: The components of the 7.62×54 AP (B-32) bullet, left: full view, steel jacket, high hardness steel core and ignition cup; right: 3D model of bullet (section), arrow shows elastic part of the core.

\subsection{Sandwich protective structures}

Here we designed a ceramics/sandwich composite system (for the same Level III of STANAG) with using $10 \mathrm{~mm}$ of alumina thickness and $t 1, t 2$ - thicknesses of the outer and inner skins of sandwich AFRP panel. Total thickness of protective system was restricted by $30 \mathrm{~mm}$ to adopt for shielding application. In this case, $20 \mathrm{~mm}$ of total thickness was occupied by sandwich structure. Influence of the foam core of sandwich on ballistic resistance was excluded. 
We investigated several projects of sandwiches where $t_{l}=0 \ldots 10 \mathrm{~mm}$ and $t_{2}=0 \ldots 10 \mathrm{~mm}$. Penetration results are shown in Table $2(\mathrm{x}-$ penetration, $\mathrm{o}-$ absence of penetration) for projects with different $t_{1}$ and $t_{2}$. Best projects (with minimum values of $t_{1}+t_{2}$ ) are highlighted. There are projects $4+4$ and $2+6$. In these cases, weight of sandwich backing is $20 \%$ less than of monolithic backing $(10+0)$. For future application second variant $(2+6)$ is better than first $(4+4)$ because area of delamination of outer skin $\left(t_{l}=2 \mathrm{~mm}\right)$ is smaller and this is good for reliability in case of the use of discrete ceramic elements (tiles) to increase of protection structure's reliability.

Table 2: $\quad$ Penetration results.

\begin{tabular}{|c|c|c|c|c|c|c|}
\hline 10 & $\mathrm{X}$ & 0 & o & 0 & 0 & 0 \\
\hline 8 & $\mathrm{x}$ & $\mathrm{O}$ & $\mathrm{O}$ & 0 & 0 & $\mathrm{O}$ \\
\hline 6 & $\mathrm{X}$ & 0 & $\mathrm{O}$ & 0 & $\mathrm{O}$ & o \\
\hline 4 & $\mathrm{X}$ & $\mathrm{x}$ & 0 & 0 & 0 & $\mathrm{O}$ \\
\hline 2 & $\mathrm{X}$ & $\mathrm{X}$ & $\mathrm{X}$ & $\mathrm{X}$ & 0 & 0 \\
\hline \multirow[t]{2}{*}{0} & $\mathrm{X}$ & $\mathrm{X}$ & $\mathrm{X}$ & $\mathrm{X}$ & $\mathrm{X}$ & O \\
\hline & 0 & 2 & 4 & 6 & 8 & 10 \\
\hline
\end{tabular}

Cross-sections of successful/unsuccessful projects are depicted in Figure 6 (a) (f). Pictures (a)-(c) show the absence of penetration. Pictures (d)-(f) - full penetration.

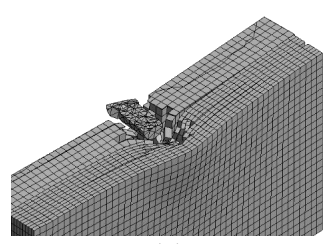

(a)

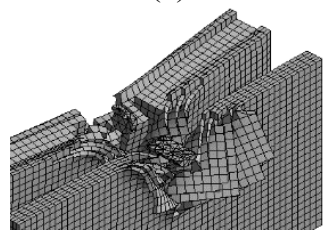

(d)

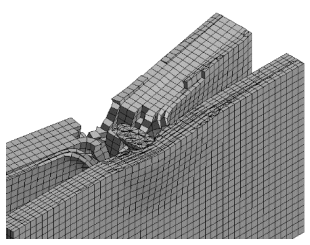

(b)

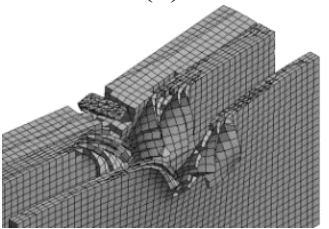

(e)

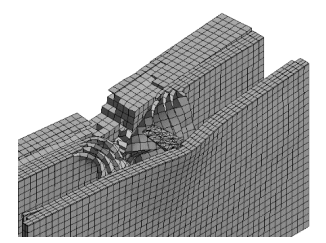

(c)

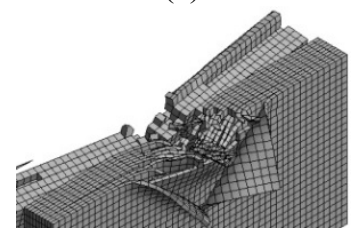

(f)

Figure 6: Pictures of penetration, projects: $\mathrm{t} 1+\mathrm{t} 2=10+0$ (a), $2+6$ (b), $4+4$ (c), $3+5$ (d), $5+3$ (e), $0+10$ (f) for the period of time 0.25 millisecond.

\section{Results and discussions}

In the design of ballistic protection structures with explicit simulations, the success of numerical models is highly depending on several features. First, the material descriptions should be modelled accurately to exhibit realistic behavior during 
penetration. For glass and alumina, these features are local plasticity at compression contact and brittle fracture at tension. For FRPs, there are complexities of fracture mechanisms because of significant anisotropy of these materials. In this work, we proposed numerically effective, low-parametric and adequate models of ceramics and FRPs to predict ballistic performance of ceramics/FRP protective structures.

The most informative thing is ballistic curve drawing after several experiments with perforation of targets with different projectile velocities. The numerical prediction of ballistic limit $V_{L}$ is highly depended of compressive plasticity, tensile strength of ceramics and size of finite element.

It is possible to select the combination of compressive yield stress and tensile strength by fitting of ballistic experimental data for concrete size of finite element. At that, the influence of material strength will decrease for increase of velocity. And the first role will play material inertia (density) for velocities higher ballistic limit. We can describe the failure of ceramics varying only two parameters: compressive yield stress and tensile strength, which was increased from static value up to $2-2.5$ times.

For failure model of FRPs (GFRP and AFRP) we offer to use again two parameters: dynamic tensile strength along fibres (or along warp and weft for fabrics) and transversal tensile strength (as breakable bonded contacts between layers). For fabric-reinforced plastics, the dynamic strength along fibre direction is 2-2.5 times higher than the static one. All other strength characteristics are not so valuable for ballistic performance. We have checked these very simple models on soda-lime glass, GFRP separately and with combination of glass/GFRP panels under steel ball ballistic loading. Comparison of experimental and numerically given ballistic curves showed very good results for engineering applications (Figure 3).

\section{Conclusions}

In this study, the perforation resistance of hard face composite structures (alumina/AFRP) against $7.62 \times 54$ AP bullet has been determined numerically on the base of experimental and FEM modelling of impact of high hardness $6.35 \mathrm{~mm}$ steel ball on soda-lime glass (as alumina analogue), GFRP plate (as AFRP analogue) and laminate glass/GFRP. The numerical models were developed using Lagrange discretization to simulate fragmentation ('death of elements' technique with remain of inertia) and complex penetration behaviors of targets. According to numerical and experimental data developed during the study, the following main conclusions can be drawn: it is possible to use only two dynamic failure parameters of ceramics and two dynamic parameters of composite backing to predict the results of ballistic impact. These models of materials gave us the possibility to optimize novel protective structure consists of ceramic face and sandwich backing. Weight of optimised sandwich part is $20 \%$ less than monolithic one with the same ballistic performance. 


\section{Acknowledgement}

This work was carried out in South Ural State University (National Research University) with the financial support of the Russian Science Foundation (project No. 14-19-00327).

\section{References}

[1] Hazell P.J. Ceramic Armor: Design and Defeat Mechanisms, Canberra, Argos Press: Canberra, pp.168, 2006.

[2] Ong, C.W., Boey, C.W., Hixson, R.S. and Sinibaldi, J.O. Advanced layered personnel armor. International Journal of Impact Engineering, 38, pp. 369-383, 2011.

[3] Bürger, D., de Faria, A.R., de Almeida, S.F.M., de Melo, F.C.L., Donadon, M.V. Ballistic impact simulation of an armor-piercing projectile on hybrid ceramic/fiber reinforced composite armors. International Journal of Impact Engineering, 43, pp. 63-77, 2012.

[4] Holmquist, T.J., Johnson, G.R. Response of boron carbide subjected to high velocity impact. International Journal of Impact Engineering, 35, pp. 742-752, 2008.

[5] Danzer, R. On the relationship between ceramic strength and the requirements for mechanical design. Journal of the European Ceramic Society, 34(15), pp. 3435-3460, 2014.

[6] Levy, S., Molinari, J.F. Dynamic fragmentation of ceramics, signature of defects and scaling of fragment sizes. Journal of the Mechanics and Physics of Solids, 58, pp. 12-26, 2010.

[7] Lee, M., Kim, E.Y., Yoo, Y.H. Simulation of high-speed impact into ceramic composite systems using cohesive-law fracture model. International Journal of Impact Engineering, 35, pp. 1636-1641, 2008.

[8] Clayton, J.D. Penetration resistance of armor ceramics: Dimensional analysis and property correlations. International Journal of Impact Engineering, 85, pp. 124-131, 2015.

[9] ESA, http://www.esa.int/Our_Activities/Operations/Space_Debris/ Hyperve-locity_impacts_and_protecting_spacecraft

[10] Kilic, N., Ekici, B. Ballistic resistance of high hardness armor steels against $7.62 \mathrm{~mm}$ armor piercing ammunition. Materials and Design, 44, pp. 35-48, 2013.

[11] Sapozhnikov, S.B., Kudryavtsev, O.A., Dolganina, N.Y. Experimental and numerical estimation of strength and fragmentation of different porosity alumina ceramics. Materials and Design, 88, pp. 1042-1048, 2015.

[12] Johnson, G.R., Holmquist, T.J. A computational constitutive model for brittle materials subjected to large strains, high strain rates, and high pressures. Proc. of EXPLOMET Conference (San Diego, California). New York: Marcel Dekker Inc., pp. 1075-1081, 1992. 
[13] Johnson, G.R. Numerical algorithms and material models for high-velocity impact computations. International Journal of Impact Engineering, 38, pp. 456-472, 2011.

[14] Deshpande, V.S., Evans, A.G. Inelastic deformation and energy dissipation in ceramics: A mechanism-based constitutive model. Journal of the Mechanics and Physics of Solids, 56, pp. 3077-3100, 2008.

[15] Clayton, J.D., Kraft, R.H., Leavy, R.B. Mesoscale modeling of nonlinear elasticity and fracture in ceramic polycrystals under dynamic shear and compression. International Journal of Solids and Structures, 49, pp. 2686-2702, 2012.

[16] Wereszczak, A.A., Morrisey, T.G., Ferber, M.R., Bortle, K.P., Rodgers, E.A., Tsoi, G., Montgomery, G.M., Vohra, Y. and Toller, S. Responses of siliceous materials to high pressure. Advances in ceramic armor IX, Ceramic engineering and science proceedings, 34(5), pp. 1-14, 2013.

[17] ANSYS $^{\circledR}$ Help, v.16.0, SAS IP Inc., 2014.

[18] Ogorkiewicz, R.M. Armor for light combat vehicles. Int. Defense Review, 35, July, pp. 41-45, 2002. 